\title{
Diversão, doença e educação dos corpos na Comarca de Vila Rica (século XVIII)
}

\section{Entertainment, illness and body education in the Vila Rica District (18th Century)}

\author{
Maria Cristina Rosa*
}

\begin{abstract}
RESUMO
Este artigo tem por objetivo compreender processos de educação dos corpos na Comarca de Vila Rica no século XVIII a partir de relações entre divertimento e doença. Optou-se por pesquisar fontes civis e eclesiásticas, contemplando o terreno das normas, bem como das contravenções, além de manuais de medicina. Maus comportamentos da população em relação à limpeza de espaços físicos e a práticas de diversão provocavam o adoecimento dos corpos e demandavam intervenções, melhorias e regulação. O divertimento associado a práticas excessivas, especialmente da população mais humilde, formada por escravos e forros, era nocivo porque prejudicava a recuperação para o trabalho, que já era desgastante. Faces de uma mesma moeda, o divertimento e a doença desgastavam os corpos, suscitavam desobediências e castigos, demandavam cuidados, eram combatidos.
\end{abstract}

Palavras-chave: Divertimento. Minas Gerais. Corpo. Educação.

\begin{abstract}
This paper aims to understand the processes of education of the bodies in the district of Vila Rica during the 18th century, based on relationship between entertainment and illness. We have chosen to research civil and ecclesiastical sources, contemplating the terrain of norms, as well as of contraventions, in addition to medical guides. Bad behaviour of the population in regard to the cleanliness of physical spaces and entertainment practices caused the bodies to become ill and demanded, improvement and regulation. Entertainment associated with excessive practices, especially among the
\end{abstract}

${ }^{*}$ Universidade Federal de Minas Gerais. Belo Horizonte, Minas Gerais, Brasil. E-mail: m.crosa@hotmail.com - https://orcid.org/0000-0003-0534-9407 
humbler population, made up of slaves and convicts, was noxious because it impaired recovery for work, which was already wearing. Two sides of the same coin, entertainment and illness wore down the bodies, led to insubordination and punishment, required care, and were fought against.

Keywords: Entertainment. Minas Gerais. Body. Education.

\section{Introdução}

A história dos divertimentos tem sido contemplada em pesquisas, especialmente no âmbito dos Estudos do Lazer. Parte importante dessa produção privilegia o estudo de práticas corporais, institucionalizadas ou não, como danças, capoeira, brincadeiras e, predominantemente, os esportes (SOARES et al., 2020). Nesse contexto, a educação do corpo ainda é pouco abordada, embora vários estudos tenham como principal argumento para a análise das mudanças que impactam ofertas e práticas de diversão o processo de urbanização que cidades brasileiras passam, especialmente no final do século XIX e início do século $\mathrm{XX}$, em que progresso e modernização são preconizados e realizados mediante melhoramentos, tanto nos espaços quanto nos comportamentos dos indivíduos.

No âmbito da Educação, esse tema tem sido abordado a partir de diferentes assuntos, como formação de professores, disciplinares escolares, castigos corporais, ginástica, esporte e infância. Os divertimentos ainda são pouco estudados, quando comparados com práticas corporais escolarizadas, todavia, é um assunto interessante porque abrange diferentes práticas, locais de ocorrência, sujeitos, costumes, corpos, sociabilidades. Estudar os divertimentos - noções, concepções, prescrições, regulamentações, resistências, sensibilidades - possibilita compreender a sociedade a partir de práticas cotidianas.

Melo (2020a) reconhece a relevância do tema para pesquisas históricas e sugere serem as vivências de diversão significativas instâncias de educação. Ao escrever sobre o parque de diversão Tivoli, inaugurado no Rio de Janeiro em 1843, enfatiza a possibilidade de interpretação de comportamentos públicos a partir da educação para e pelo entretenimento, pois "todos deveriam aprender a se portar nos espaços de diversão, na mesma medida em que esses espaços difundiam novas formas de se portar" (MELO, 2020a, p. 4).

A noção ou entendimento do que é educação do corpo tem sido trabalhada por diferentes autores, como Melo (2020b); Soares (2014, 2000); Taborda de Oliveira (2006), Moreno et al. (2012), que buscam "identificar permanências e rupturas, no que diz respeito aos modos como uma dada sociedade desenha 
formas de intervenção voltadas aos corpos" (SOARES, 2014, p. 219). Ao escrever sobre essa noção, esta autora chama atenção para os "processos que incidem sobre nossos corpos para modificar e revelar comportamentos e condutas as mais íntimas e ocultas, tanto quanto as mais visíveis e públicas" (SOARES, 2014, p. 219). Dialogando com e considerando essa noção, este artigo objetiva compreender, na Comarca de Vila Rica no século XVIII, processos de educação dos corpos a partir de relações entre diversão e adoecimento dos corpos.

Este estudo é importante porque, como afirma Fonseca (2014, p. 32), nessa temporalidade as concepções educacionais "não se voltavam, necessariamente, para uma perspectiva escolar de educação, mas tratavam de questões mais amplas, das ações e práticas que formassem indivíduos úteis socialmente, ou seja, os súditos cristãos, leais ao Estado e à Igreja", entre elas a ocupação contra o ócio. E, conforme afirma, a história da educação deve dar mais importância à "dimensão não escolar da educação, necessária para a compreensão dos processos e das práticas educativas fortemente presentes nos séculos anteriores à independência" (FONSECA, 2014, p. 16), cujos rastros encontram-se em tipos e espécieis documentais diversos, geralmente dispersos e manuscritos.

Seguindo este caminho, este estudo explorou o terreno das normas, mediante análise de editais, posturas e pastorais expedidos tanto pela Igreja quanto pelo Estado, principais instituições de poder que ordenavam, proibiam e recomendavam comportamentos e regulamentavam os costumes e a moral, almejando ordenar o bem comum; bem como o terreno das contravenções por meio do estudo de transgressões, delitos e desvios descortinados pela justiça eclesiástica e civil, que possibilitaram compreender como as pessoas se aproximavam ou se afastavam de padrões e, ainda, como os reinventavam. Nas fontes pesquisadas a população escrava emergiu, com força, como infratores, acusados, vítimas. Além disso, foram mobilizados manuais de medicina escritos por cirurgiões, um dos principais agentes das artes de curar presentes nessa ambiência.

A Comarca de Vila Rica, formada por núcleos urbanos e rurais, como arraiais, distritos, freguesias e vilas, ocupava o centro da Capitania de Minas em termos econômico, populacional e comercial. A sede administrativa era Vila Rica. Outro centro urbano importante era a Vila de Nossa Senhora do Carmo, elevada a cidade de Mariana em 1745 para sediar o Bispado. As duas localidades concentravam características e práticas relativas ao urbano, como concentração populacional; edificações; matriz ou catedral; pontes, calçamentos e fontes; sublevações e assuadas; aclamações festivas; comércio de mercadorias produzidas no país e no exterior; trânsito de pessoas e mercadorias; diversidade de ofícios e oficiais; variedade de práticas de divertimentos. 
Nessa temporalidade, a diversão era vista como desvio do útil para o inútil, afastamento de um trabalho necessário, de qualquer ocupação séria para entrega a outra atividade, menos necessária. Divertir-se era "tirar, ou diminuir a aplicação a algum estudo, negócio. Desviar de alguma ocupação, empresa", de ações virtuosas (BLUTEAU, 1712-1728, p. 259).

Na Comarca de Vila Rica, a diversão da população, predominantemente masculina e escrava, estava associada principalmente a um significado negativo. A ela eram agregados ociosidade, preguiça, desvio, excesso e tempo para fazer coisas inúteis. $\mathrm{O}$ divertimento era considerado algo que não edificava, não era sólido, "espinho entre flores". Algo inútil que divertia, dava prazer, mas era também perigoso. Buscava-se a regularização das experiências: um afastamento ou distanciamento dos desvios, vícios, desregramentos, excessos, dores e sofrimentos, almejando o governo das ações simultâneo ao processo de civilização.

Em diferentes discursos, como eclesiástico, jurídico e médico, e em diversas práticas de regulação dos comportamentos, os divertimentos eram associados ao vício, ao pecado e, também, ao adoecimento dos corpos ${ }^{1}$. Quando se falava em diversão tinha-se como propósito demonstrar a nocividade, o malefício e a perniciosidade de uma prática dita como prejudicial. Dessa forma, era estabelecido o lícito e moral. Entre os bons valores e procedimentos, exaltava-se, destacava-se o trabalho/virtude e negava-se o vício/ociosidade que causava doenças e permitia prazeres, divertimentos.

Neste contexto, alguns locais e formas de diversão se destacavam, eram mais temidos, como as vendas onde, além de secos e molhados, havia prostituição, jogos, contendas, negros fugidos, mercadorias desencaminhadas por roubos ou furtos; as casas de alcouce em que, apresentando uma situação propícia para que as pessoas ofendessem a Deus, havia batuques, calundus, concubinatos, bebidas e danças; a rua onde ocorriam ajuntamentos, jogos, passeios, trânsitos de pessoas e práticas, festas; as casas de jogos em que havia consumo de bebidas e prostituição, jogos permitidos e proibidos, especialmente os jogos de carta; os batuques ou ajuntamentos ilícitos em que além de danças

1 Discursos e práticas presentes, por exemplo, na documentação produzida pela Câmara Municipal, em que atuavam juízes, vereadores e médicos contratados, e que permitiu entender a regulamentação da vida cotidiana, os usos de espaços urbanos e suas transformações, bem como costumes, reformas e transgressões que ocasionavam a necessidade de alterações e de novas regras; nas devassas eclesiásticas realizadas por visitadores durante as visitações diocesanas e pastorais e que permitiram identificar e analisar mandados, proibições, recomendações, advertências, regulamentações e ordenações que buscavam consertar erros e costumes considerados impróprios, verificar o cumprimento das Constituições e proceder nas deficiências; e em manuais de medicina escritos a maioria das vezes por cirurgiões em que valores não só científicos, mas também morais eram atribuídos a comportamentos. 
consideradas desonestas ocorriam músicas, cantos, tambores, vozes, distúrbios, bebedices e mistura de sexos; as festas, especialmente as populares, como saraus, batizados, batuques e bailes, em que corpos de ambos os sexos se ajuntavam, dançavam, cantavam. Divertimentos lícitos e ilícitos que se misturavam e tinham a noite, período de menor vigilância e regulação, como tempo de maior predominância e, consequentemente, de mais excessos, sociabilidades. Nessas ocasiões, devido à reunião de práticas e pessoas, afloravam possibilidades de pecar, praticar vícios, adoecer.

A compreensão de doença na América Portuguesa era estabelecida por conhecimentos elaborados por práticas culturais diversas que remetiam à medicina dita oficial, ao conhecimento empírico, ao saber popular, à magia e à religião. Vertentes que se (con)fundiam, não só no entendimento do que era doença, mas também nos diversos tratos corporais - preservação, purificação e cura (VIGARELLO, 2001), seja por métodos e medicamentos utilizados, seja por quem exercia a ação. Como outras manifestações da cultura, os conhecimentos, saberes e práticas da medicina eram formados pela diversidade. A arte de curar realizada na Comarca de Vila Rica podia retratar a dinâmica desse universo cultural em que a medicina, exercida por médicos, cirurgiões, boticários, barbeiros, curandeiros, feiticeiros e parteiras, mostrava concordâncias, divergências e conciliações nas diferentes formas de tratar os corpos. Como aponta Dias (2002), que escreve sobre o corpo nas Minas, especialmente na época da mineração, tendo como referência a obra Erário Mineral, escrita por Luís Gomes Ferreira e publicada em 1735, havia a formação de "uma cultura híbrida dos costumes relativos ao corpo humano [...] pois contém receituários, boticas e feitiços das tradições populares do norte de Portugal, dos índios carijós, de escravos mina e bantu" (DIAS, 2002, p. 325).

Para a medicina exercida principalmente pelos cirurgiões, que tinha como um dos princípios a observação dos corpos e a experiência adquirida mediante a prática, a doença baseava-se sobretudo na alteração dos humores, a acrimônia, que constituíam os temperamentos. Esses eram influenciados principalmente pelo clima, alimentação, ventos, qualidade da água, umidade e modo de viver. E na Comarca de Vila Rica não foi diferente. Fatores, como comida de má qualidade, miséria, trabalho excessivo, qualidade do ar e da água, imundície, permitiam o surgimento e propagação de doenças que eram combatidas principalmente com ações administrativas das Câmaras, que manifestavam necessidade de intervenções para a vigilância dos diversos agentes, bem como para a melhoria dos maus comportamentos da população. Entre essas ações a limpeza de espaços físicos e a regulação de práticas de diversão. 


\section{Limpeza de espaços físicos}

A sujeira acumulada, entulhos nas ruas e o uso indevido de alguns lugares motivavam enfermidades. A limpeza de locais públicos, portanto, era essencial para evitá-las e foram várias as ações. O edital de 04 de junho de 1791 publicado pelas ruas da cidade de Mariana determinava "que nenhuma pessoa de qualquer qualidade, e condição que seja despeje, ou lance águas sujas, ou outras quaisquer imundícies, o esterqueirão nos referidos canos, ruas, e becos desta cidade" (AHCMM, 1791), e estabelecia pena para os transgressores, sejam livres ou escravos. Eram diversos os problemas com o esterco e com as esterqueiras apontados desde o início do século como meio de proliferação de doenças contagiosas. Havia intervenções que falavam sobre o seu uso principalmente em épocas de epidemia, quando o cuidado devia ser redobrado.

Da mesma forma, a qualidade da água, que não devia ser infeccionada nem suja, revelava-se como um item importante para se evitar moléstias. Em Vila Rica, por exemplo, os moradores da praça solicitaram o encanamento da água do chafariz para evitar enfermidades (APM, 1751). Já em Mariana e seu termo, por vários anos, foram publicados editais sobre o uso indevido das fontes. O edital de 28 de janeiro de 1775 publicado nas ruas da cidade proibia o uso de chafarizes e fontes públicas para lavar roupas ou outras quaisquer coisas $(\mathrm{AHCMM}, 1775)^{2}$. Quais eram os usos autorizados das fontes? A água era usada para cozinhar, beber, banhar os corpos, lavar roupas e objetos. No entanto, esse uso requeria asseio, pois nas fontes pessoas vinham apanhar água, que devia estar limpa. Seria a água também utilizada para diversão, uma vez que as fontes eram lugares em que outras práticas, que não o trabalho, aconteciam? Esperava-se, pois, não só a limpeza do espaço como também das práticas que aconteciam.

Outro fator importante eram os ares corruptos, que podiam causar epidemia. Havia, pois, editais da Câmara, como de Mariana, que determinavam a sua purificação: "façam por espaço de oito dias em todas as noites sucessivas grandes fogos as suas portas, queimando junto com samambaia, por outro nome [feto], ervas cheirosas, e balsâmicas" (AHCMM, 1780). Para Vigarello (1996), o conforto e fortalecimento do corpo são alguns referenciais terapêuticos do perfume. Ao falar sobre a transformação das defesas contra a peste, o autor explica que, associadas à queima do fogo, foram sendo inseridas substâncias aromáticas, justificando a maior eficácia na purificação ou correção do ar. 
O costume de moradores, criadores, atravessadores e vendedores trazerem porcos soltos pelas ruas de vilas e arraiais também trazia prejuízos $\grave{a}$ saúde relacionados à sujeira e à aparência, por serem esses animais imundos. Em Vila Rica, ordenava-se aos criadores de porcos conservarem esses animais em lugares próprios, impedindo-os de andar pelas ruas do arraial (APM, 1733). Deviam, pois, serem recolhidos. No termo de Mariana, o incômodo e dano causados pelos porcos à aparência de casas de morada, prédios e igrejas demandavam representações de moradores de algumas localidades à Câmara, em que pediam providências.

Do mesmo modo, havia editais e posturas que falavam sobre a qualidade da alimentação, especificamente sobre o comércio em algumas lojas de coisas corruptas. A carne e o beiju feito com a farinha de milho eram os alimentos comumente citados. A carne tocada, infectada ou corrupta e com mau cheiro parecia ser um problema persistente. Em Vila Rica, as posturas de vários anos, como $1724,1738,1745$ e 1761, tentavam vigiar e punir a presença de carne estragada em açougue e talhos da Vila bem como os marchantes que as vendiam. Em Mariana, as posturas dos marchantes, estabelecidas pela Câmara em 18 de setembro de 1771, além de estabelecerem preços da carne, diziam que eles "não cortarão por modo algum gado que esteja tocado, ou infectado pena de perder o mesmo gado e pagarem quatro oitavas de ouro por cada boi, e da mesma sorte o que se presumir estar mordido de cobra" (AHMI, 1771, p. 90).

$\mathrm{Na}$ Comarca de Vila Rica, as ações das Câmaras Municipais em relação às doenças eram similares às anunciadas por Roberto Machado et al. (1978), que afirmam não existir na colônia uma medicina social. Não havia higiene pública que se relacionava com o social. O que existiu foram respostas para sanar problemas da relação com a sujeira e a doença a partir de denúncias e fiscalizações, em que se destacava a ação dos almotacés. Eram ações fragmentadas, punitivas e restauradoras, não existindo preocupação com prevenção, planejamento ou avaliação. Restringiam-se, simplesmente, a ações paliativas ou amenizadoras. Na verdade, eram características comuns de ações que diziam respeito às diferentes dimensões da vida na América Portuguesa, como saúde pública, (re)estruturação urbana, governo de práticas sociais e regularização de comportamentos, como dos divertimentos. 


\section{Regulação de práticas de diversão}

Diversão, bebida, prostituição, jogos, brigas eram ações que não só a Câmara, mas também a Igreja fiscalizavam e tentavam constantemente vigiar. Almejava-se não só a limpeza dos espaços, como dos corpos que por eles circulavam e das práticas consideradas viciosas. Uma imundície, por conseguinte, que não era só física, mas predominantemente moral, o que remetia aos usos e costumes. Entre os diversos discursos dirigidos para a doença e o divertimento, destacava-se o médico, que tinha papel relevante, colocando entre as causas da doença, os hábitos de vida, sendo enfatizados os dos negros. Com isso, a diversão aparecia, entre outras práticas, como motivo.

Na obra "Observações sobre enfermidades dos negros"’, Dazille (1801) aborda sintomas, causas, formas de curar e prevenir enfermidades de negros, tendo como referência a medicina prática e a observação atenta de mudança dos temperamentos influenciados pelo modo de viver. Entre as principais causas de doenças por ele identificadas encontram-se a má alimentação ou alimentação insuficiente, a falta de roupa, o trabalho excessivo ou superior às forças, a passagem repentina do calor ao frio e o gênero de trabalho e de vida, como também as formas de descanso, a vida sexual e o consumo da aguardente.

Além do trabalho excessivo, como cita Dazille (1801), para as colônias em geral, o tempo de descanso também surgia como um estímulo às doenças, pois as raras folgas eram utilizadas para a libertinagem e não para a reparação necessária. A noite, principalmente, não era para descanso, restauração. Nela se buscavam divertimentos, aguardente, deleites sensuais e a satisfação dos desejos, prazeres dos corpos - a que os negros eram inclinados. É “deste tempo, que eles roubam ao único descanso que podem tomar, sendo empregado nos prazeres precedidos, e seguidos de penosas carreiras, lhes resulta um abatimento, conseqüência, de que é bem difícil salvá-los" (DAZILLE, 1801, p. 31). Assim, além de trabalho demasiado, má nutrição, roupas insuficientes, injúrias do ar, tratamento inadequado nas doenças, ocorria a entrega quase desmedida aos deleites sensuais e à bebida, não conservando, pois, a saúde.

Ao descanso estavam associados divertimentos, bebidas, jogos, libertinagens, festas, ajuntamentos, batuques, prazeres do corpo e pecados da carne, que, segundo as Constituições Primeiras do Arcebispado da Bahia de 1707 (VIDE, 1853), incluem sodomia, bestialidade, molície, adultério, incesto,

3 Obra escrita por Jean-Barthélemy Dazille, cirurgião francês das tropas na ilha de São Domingos, sobre doenças de cativos nas áreas coloniais. 
estupro e rapto, concubinato, alcovitaria e alcouce. Alguns muito presentes no cotidiano da Comarca.

Conforme Ferreira (2002) $)^{4}$ aponta, os pretos, especificamente os que viviam nas Minas, eram muito afeiçoados aos desmanchos de mulheres e à cachaça. Aos corpos femininos eram associadas doenças, sendo recomendado cuidados no trato. Na freguesia da Cachoeira, Manuel dos Santos Sampaio estava amigado com uma negra, sua escrava, que já havia vendido e comprado por duas vezes. Conforme consta, os cirurgiões lhe aconselharam que a largasse, pois, ao contrário, haveria de morrer (AEAM, 1727). Por quê? Afinal, como era público, eles estavam juntos há anos. Seria preocupação com doenças? Quais os males provenientes desse corpo feminino?

Para Dazille (1801), as doenças venéreas, resultado de muita depravação, eram muito comuns entre os negros e o tratamento era difícil, pois geralmente se complicavam com outras doenças. Conforme alega, em alguns casos, a doença persistia, pois geralmente os tratamentos eram pouco metódicos, a libertinagem excessiva e os negros, muitas vezes, não acusavam a presença da moléstia. Além disso, revela que o vírus atuava mais efetivamente no corpo cansado, mal alimentado e enervado, mais propenso a danos graves e menos inclinado à cura. Dessa forma, os corpos dos negros e seus descendentes eram muito suscetíveis devido aos tratamentos, por outras palavras, aos maus tratos. Por ser a mais frequente entre as doenças venéreas, destaca a gonorreia, inclusive a virulenta e a que é chamada caída no escroto. Na devassa que trata da morte do escravo André Courano, o cirurgião Manuel de Araújo Cortes, que morava na rua de São José de Vila Rica, foi chamado no dia 08 de novembro de 1742 (AHMI, 1742b), por volta da meia-noite, para atender Francisco Marques Coimbra. Em seu depoimento, indica a presença em Francisco Marques Coimbra da gonorreia e consequências que, como explica Dazille (1801, p. 135), eram "dificuldades de urinar produzidas por úlceras, e prisões da uretra", além do uso do banho como forma de tratamento do doente.

A sífilis, conhecida por gálico ou bouba, também tinha presença marcante nas Minas, como mostra Antônio José Vieira de Carvalho, tradutor do livro de Dazille, ao explicar uma enfermidade por nome pian, a que, particularmente nas Minas, chamam bobas. Essa doença também aparece em um libelo que Domingos Francisco de Carvalho moveu contra Antônio Labedrene sobre dívida de fazendas em uma loja. O réu, por reconvenção, cobrava ao autor do libelo

4 Esta obra foi publicada em 1735, em Lisboa Ocidental, na oficina de Manuel de Rodrigues. A versão utilizada é uma edição fac-similar organizada por Júnia Ferreira Furtado, publicada em 2002, e que inclui estudos críticos sobre a obra escrita por Ferreira, glossário e glossário médico. 
uma dívida pelo serviço de cirurgião por lhe ter curado um escravo de bulba, com medicamentos e cirurgia perigosa, de doença maligna que o autor trouxe do sertão, entre outras ações de assistência a escravos (AHMI, 1741).

A tentativa constante de normatizar o trânsito e o comércio realizado pelas negras de tabuleiro como também a vigilância à permanência de negras, forras ou escravas, nas vendas, embora quase sempre nas mãos dessas mulheres (FIGUEIREDO, 2017), podiam estar relacionadas a essas moléstias e às tentativas de regularização dos comportamentos, inclusive de protestos e rebeliões (FIGUEIREDO, 2017). Os descaminhos dos corpos, como a prostituição, precisavam ser direcionados, governados, principalmente em épocas de epidemias, para preservar quem ainda não tinha sido contagiado. Vale ressaltar que se fala pouco ou quase nada sobre os prazeres e desejos dos corpos negros, esboçados por músicas, comidas, bebidas e outros deleites. São ressaltados os castigos corporais recebidos por negros e seus descendentes, que constituíam a grande parcela da população da Comarca de Vila Rica. Quando o divertimento era exaltado, a pretensão é mostrar problemas que este causava ao trabalho ou ao corpo trabalhador, principalmente como estímulo ao surgimento de doenças. Outro aspecto ignorado era o descanso como recuperação das energias despendidas no trabalho e nos divertimentos.

O silêncio das fontes, no que se refere a "lazer, festas e outras atividades semelhantes" dos escravos, é indicado por Lara (1988, p. 230), em seu trabalho sobre violência nos Campos dos Goitacases. No entanto vale considerar que, mesmo com a ausência, ou melhor, com apontamentos restritos sobre os divertimentos nas fontes consultadas neste trabalho, pode-se perceber que diversas situações eram propícias a essas manifestações, como práticas mencionadas em processos que averiguavam delitos, que ocorriam principalmente à noite, em ruas, vendas, casas de alcouce, no adro da igreja, durante o passeio, no momento que se estava sentado à porta das casas ou saindo da missa. Nessas ocasiões, corpos adoeciam com ferimentos causados por pancadas, assaltos, contendas, bulhas e outros excessos, sendo essas ações muitas vezes movidas por ciúmes, dívidas, bebidas, prazeres, rixas, desprazeres e jogos. Contudo, certos fatores associados ao universo da diversão devem ser evidenciados como motivadores de doenças: as bebidas, citadas por Dazille, e da mesma forma as agressões físicas. 


\section{Sobre as bebidas}

Na América Portuguesa, as bebidas alcoólicas eram muito consumidas. Figueiredo (2004) cita bebidas feitas com mandioca, cana-de-açúcar, trigo, uva e milho. Produzidas ou importadas, destiladas ou fermentadas, remédio ou estímulo ao vício, além de explicitar a intensa troca cultural, provocavam interferências na economia, devido à produção em larga escala de algumas. Gerando recursos fiscais, por serem produtos de troca, podiam ser causa de alegrias, mas também de tristezas, pelas doenças e outros desequilíbrios. Mas, na arte de curar, algumas, como a aguardente e o vinho, eram utilizadas como medicamentos, sendo, pois, diversos os usos. Na Comarca de Vila Rica destacava-se o consumo da aguardente ${ }^{5}$. Os escravos, especialmente, bebiam para aguentar o duro trabalho na mineração, muitas vezes dentro da água fria por longos períodos, além da exposição ao clima. O seu uso diminuia o número de mortes. Como sugere Luciano Figueiredo (2004), constitui complemento dietético à fraca alimentação proporcionada pelos senhores.

Ferreira recomenda, em uma advertência para a saúde, um copinho de aguardente do reino ${ }^{6}$ diariamente pela manhã para pessoas que comeram alguma coisa e um dedal dessa bebida para aqueles que não comeram nada, podendo ser substituída por chá ou chocolate. Ela também era muito usada na composição de remédios, como emplastos, e na forma de lambedor. "A quantas pessoas parecerá engano o dizer-se que os membros abrasados com o incêndio da erisipela se curam aplicando-lhe panos molhados em aguardente ou espírito de vinho", pergunta o autor do "Erário Mineral" (FERREIRA, 2002, p. 226).

A aproximação entre a bebida e escravos é feita por diversos autores e na Comarca de Vila Rica falava-se especialmente do consumo da aguardente, cujo uso contínuo e excessivo foi condenado por Ferreira (2002), porque levava a doenças, como a obstrução, muito comum na região. Ao alertar os senhores de que todos os escravos bebiam, este autor afirma que muitos morriam devido a esse vício ou ao uso de bebida, que, além de danificar a saúde, podia tirar a vida, crédito ou fazenda. O estudo de Mendes, citado por Silva (1999), também

5 Embora alguns autores, como Figueiredo (2017) e Silva (2015) que estudam as bebidas neste contexto social, façam diferenciação entre os termos e expliquem os significados atribuídos, neste trabalho aguardente, aguardente da terra e a cachaça aparecem sem distinção. Optou-se por respeitar as fontes, sem aprofundar nessa questão.

6 Nota-se que esse cirurgião barbeiro recomenda sempre o uso da aguardente do reino, dita a melhor, o que não quer dizer que a aguardente da terra não fosse utilizada para essa e outras finalidades por ele recomendadas. 
indica a associação entre o consumo excessivo de aguardente pelos negros e a ressecação dos bofes, uma doença crônica. Da mesma forma, o uso abusivo da cachaça é revelado por Romeiro e Botelho (2003), que associam a bebida ao surgimento de certas doenças, como o endurecimento (em) arco da córnea. Outras doenças são citadas por Silva (2015), como a cirrose hepática.

Além de trazer prejuízos por adoecer os escravos, que retiravam da terra a riqueza, a bebida causava desordens, afastamento do trabalho. Assim, a Câmara de Vila Rica, em resposta a uma petição feita e assinada por mineiros, aceitou proibir a venda, nos domingos e feriados em honra de Deus, de aguardente e outros alimentos, devido ao que mencionam (ANNAES DA BIBLIOTHECA NACIONAL DO RIO DE JANEIRO, 1936).

Os motivos alegados não se sabem, provavelmente era o sossego e aquietação deles, pois nos dias de descanso a aguardente junto a outros estímulos era causa de comportamentos considerados prejudiciais, inclusive os de resistência. Como mostra Figueiredo (2017), na América Portuguesa, de maneira semelhante ao que ocorreu na Europa durante a Idade Moderna, protestos, resitências, movimentos políticos compostos de grupos populares eram atrelados ao consumo da bebida, num movimento de desqualificar ações de rebeldia e deslegitimar as reivindicações.

Mas a bebida suscitava outros comportamentos em outros dias e não era consumida apenas por negros e seus descentes. Na freguesia de Catas Altas, Manuel da Silva Neves é denunciado de viver na bebedice, pecado escandaloso, sendo considerado um bêbado perene (AEAM, 1722-1723). Nas devassas eclesiásticas havia denúncias de seculares e eclesiásticos que viviam pelas vendas e tabernas embebedando-se com vinho, aguardente e cachaça. Com a bebida em demasia, muitos perdiam o juízo e cometiam maus tratos, falavam palavras descompostas, cometiam excessos, faziam parvoíces e davam escândalos, como o padre Alexandre Pereira Tavares que, segundo dizia Antônio Rodrigues, muitas vezes se embebedava com cachaça e fazia confusão (AEAM, 1726).

A aguardente era ingerida em ocasiões de divertimentos, como jogos, batizados, casamentos, ajuntamentos e conversas nas vendas. E dessas convivências surgiam contendas, bebedices e bulhas, havendo até ferimentos causados por pessoas que, nesses locais, em dias comuns ou em feriados e dias santos, se excediam no consumo. Em Lavras Novas, freguesia do Itatiaia, José Ferreira Lisboa teve questões com o capitão do mato Luís da Costa, que lhe deu algumas facadas, devido às quais esteve em perigo de morte (AHMI, 1742a). Em seu depoimento, o capitão Francisco Veloso dos Santos, que presenciou a cura dos ferimentos pelo cirurgião, em sua casa, disse que na noite do ocorrido José Ferreira Lisboa estava turbado de juízo, devido à bebida. 
Por volta da uma hora da madrugada, na rua do Senhor do Bonfim, Francisco, crioulo, escravo do padre Joaquim Pereira, que morava no Ouro Preto, foi espancado e ferido (AHMI, 1800). Algumas testemunhas denunciavam o alfaiate Pedro, crioulo forro, que foi preso como responsável pelo delito. Segundo Catarina da Costa, mulher parda forra, Pedro Crioulo, forro, havia entrado em sua venda, comprado e bebido cachaça, ficando fora do seu juízo. Posteriormente, ouvira seu filho Serino dizer que, naquela mesma noite, ele fora assistir à fundição de um sino no Ouro Preto, onde esteve com Francisco Crioulo, que estava embriagado. Saindo dali, Pedro, com uma faca pequena, esfaqueou Francisco. Conforme Serino da Costa Pinheiro, também testemunha na devassa, ele havia ido assistir à fundição junto com Francisco, crioulo, e Pedro, crioulo forro:

ambos tinham bebido cachaça com a qual se embriagaram e em companhia dele testemunha começaram a brincar um com outro por serem muito amigos e naquele brinquedo dera o dito Pedro duas facadas no corpo do dito Francisco com as quais lhe fizera os ferimentos constantes do auto isto em ar de brinquedo e não para sim querer executar [...] (AHMI, 1800, fl. 6v).

Não se sabe a relevância social de assistir à fundição de um sino. No entanto, era um acontecimento que atraia a presença de várias pessoas que, a partir dessa motivação, encontravam amigos, bebiam, divertiam-se e acabavam, algumas vezes, provocando ferimentos. Em que tipo de brincadeira se utilizaria uma faca? Depois do ocorrido, ainda naquela noite ou madrugada, Catarina da Costa viu os ferimentos de Francisco, que lhe solicitou a cura. Estaria ela ainda na venda? Por que foi procurada para curar tais ferimentos? Será por haver em sua venda cachaça?

A aguardente era percebida muitas vezes como problema, pois gerava doenças, tirava os negros do trabalho, causava desordens e rebeldias, mas ao mesmo tempo era muito apreciada por proporcionar prazeres e sociabilidade. Embora Guimarães (2005) a destaque como portadora de conteúdo político, por favorecer condições de preservação do escravismo, ele evidencia situações em que era utilizada pelos escravos como forma de resistência, revelando, na dinâmica da vida, o caráter contraditório dos diversos usos e atribuição de significados. Estudar o consumo de bebidas alcoólicas, bem como os espaços de consumo, como tabernas e botequins, possibilita compreender formas de sociabilidade, relações comunitárias, modos de vida e formas de estar em sociedade (ALGRANTI, 2011). 


\section{Sobre as agressões físicas}

Já as agressões físicas movidas pela bebida, ou não, eram muito comuns. Elas aconteciam no recolhimento das casas, em situação de trabalho, de divertimento e em circunstâncias em que havia castigos corporais. Delas resultavam os ferimentos que pareciam ser tão comuns que Ferreira (2002), ao falar da forma como exercia a medicina e cirurgia e ressaltar tratamentos por ele utilizados na cura, que tinha por base a sua experiência, cita a cura de feridas. Ele diz:

quem haverá que não se admire vendo sarar feridas horríveis e fluxos de sangue implacáveis sem se aplicar remédio algum sobre as tais feridas, mas deitando somente os pós simpáticos sobre o sangue ou sobre o instrumento que feriu, com tal condição que o sangue esteja ainda fresco?! (FERREIRA, 2002, p. 226).

A presença da violência na vida diária nas Minas é ressaltada por Dias (2002), que alude ao costume de Ferreira sempre trazer, pelas "trilhas inóspitas" que percorria a cavalo, "uma boa receita para os ferimentos de pólvora no rosto ou para curar feridas causadas por excesso de açoites". Ao manifestar o conhecimento desse cirurgião sobre as ervas, plantas e remédios, adquiridos no convívio com paulistas e carijós, a autora evidencia que ele

bem sabia o impacto dos revezes causados por males repentinos, por facadas, quedas bruscas, que causavam fratura nos ossos, mordidas de cobra, acidentes de percurso, seja no desbravar matas para plantar roças, seja no costume de minerar dentro dos rios (DIAS, 2002, p. 53).

Faltou acrescentar: nos divertimentos, como ressaltam Rosa e Silva e Santos (2020).

Eram contendas, dúvidas e bulhas sucedidas em vendas, adros de igrejas, casas de jogos, ruas, batuques etc., em tempos e espaços de diversão, que tinham a presença marcante de negros e seus descentes e aconteciam, principalmente, à noite, tempo de menor visibilidade, o que possibilitava o maior trânsito de pessoas fugidas bem como as fugas (GUIMARÃES, 2005). 
Teresa Rodrigues de Jesus foi ferida à noite, por volta de oito horas, na praça de Vila Rica. Como consta no termo feito pelo tabelião João Peres Souto e pelo cirurgião aprovado, Luis Pinto Ribeiro, que a curou e assistiu, tinha uma ferida na "cabeça acima da fonte da parte direita onde chamam os ossos [escumezos] e protezos do tamanho de quatro dedos entraves com contusão, de couro e carne cortada já curada com dois pontos, e declarou o dito licenciado ter ofensa no crânio" (AHMI, 1749). Além dos gritos que alcançaram pessoas em suas casas e em ruas vizinhas, houve vozes e sons de porretadas que denunciaram a confusão. Algumas pessoas passavam, umas estavam conversando na rua, outras estavam à janela. Alguns viram o vulto, outros o corpo ensanguentado. Conforme Manuel Francisco Ribeiro, que morava na praça, estavam conversando com ele naquela noite, à sua porta, um ourives e a parda. Ficando conversando, na venda, apenas ele e Teresa, chegou um negro e lhe fizera o ferimento. Era noite e havia pessoas em atividades diversas que pareciam permear o terreno da diversão e/ou trabalho.

Já o ferimento causado por Manuel de Barros Silva em Antônio Pacheco foi assistido pelo cirurgião Francisco Coelho [Siqueira] (AHMI, 1747). Apenas se sabia que os dois estavam jogando ou brincando o entrudo no terreiro de uma casa, enquanto outras pessoas também brincavam pelos campos. No entanto a gravidade do ferimento que atingiu a cabeça levou Antônio Pacheco à morte.

Era noite. Na casa de Eugênia Mexia, no arraial de São Sebastião, termo de Mariana, acontecia um batuque de negros, em que pessoas se divertiam. Lá estavam Jorge Crioulo e seu irmão Inácio:

que estava justo e assalariado com Miguel Francisco e este tinha mandado chamar ao dito Ignácio e não dando este ouvidos ao dito chamado foi continuando no seu divertimento de que lhe resultou vir o dito Miguel Francisco com um pau, e entrando na porta da casa chamou o Inácio, e botando-lhe a mão nos peitos o pegou, e entrou a dar-lhe com o pau que levava, e nesta luta caiu o dito Miguel Francisco e deu com a cabeça em uma pedra que estava atrás da porta de que sucedo fazer-lhe uma contusão a qual ela testemunha lha curou sem que o réu tivesse por ter a dita queda, e contusão por estar muito afastado do dito Miguel Francisco nem tinha na dita ocasião o réu consigo arma nem pau algum [...] (ACSM, 1782)7.

7 O nome da pessoa ferida Miguel Francisco também aparece como Miguel Fernandes. 
O depoimento de Valéria Teresa de Jesus, parda forra, referia-se aos artigos do libelo de contrariedade feito pelo réu, Jorge Crioulo, escravo de Sebastião Gomes de Abreu, preso por ser acusado em uma devassa de ter ferido a cabeça de Miguel Francisco. Como Valéria, as outras testemunhas do réu também confirmaram o seu bom procedimento. Como alegaram, Jorge estava com seu irmão em um brinquedo, quando se instaurou uma confusão iniciada por Miguel Francisco, ao atacar, puxar e dar pauladas em Inácio. Jorge agiu em defesa do seu irmão e, na contenda, Miguel acabou tropeçando e se machucando sozinho. A agressão que moveu a devassa e consequentemente o livramento foi apresentada como acidente, mas o contexto era o do batuque e envolvia, além das práticas concernentes à diversão, ofensas a um escravo. Além disso, próxima à casa em que se realizava o brinquedo, estava a venda de Bartolomeu Dias da Silva, aberta, porque era dela que ele ouviu o reboliço na casa de Eugênia Mexia e foi, apressadamente, verificar o que era.

Por ser Inácio assalariado de Miguel, o que parecia ser escravo de ganho, este tinha o direito de, a qualquer tempo, exigir os seus serviços, a sua atenção? Por que Inácio não deu ouvidos ao chamado do senhor? Quais os significados desse divertimento para um e outro e sua relação com o trabalho? Como Inácio participava da brincadeira?

O divertimento associado a práticas excessivas surgia como algo nocivo, porque prejudicava a recuperação para o trabalho, que já era desgastante. A doença ou falta de saúde agregava trabalho e diversão. A doença talvez possa ser considerada como o divertimento um descaminho, um espinho entre as flores, devido aos desvios dos corpos. Na Comarca de Vila Rica os descaminhos demarcaram traços densos na dinâmica social, que talvez possam ser vistos como empecilhos ao desenrolar do processo de civilização.

\section{Considerações finais}

Na Comarca de Vila Rica, educação, diversão e doença estavam entrelaçadas, como também estavam negros, rusticidade, ilicitude e escravidão. No âmbito da diversão, destacavam-se os descaminhos quando o governo e direção das práticas tentavam predominar, quando o econômico pretendia reger a vida cultural e nortear ações e composições, como descanso, gosto, divertimento e tratos dos corpos. Esse enfoque da diversão trazia, entre suas consequências, a tentativa da institucionalização das práticas, ação que reclamava intervenções e estratégias múltiplas, pedagogias, regularização dos corpos bem como transgressões e irregularidades. 
Assim, as tentativas de privação do deleite, do gosto ou do gozo, ainda que lícitos, eram algo que não podia passar despercebido, pois se almejava governo e vigilância das vontades e dos desejos dos corpos diante dos sabores, contatos, cheiros, sons, mesmo de outros corpos. Exigia-se, pois, uma educação dos sentidos. Prazeres e regalos deviam ser desterrados. Criavam-se novas sensibilidades? O corpo vicioso, entregue a alegrias e vícios, era considerado doente e merecia atenção, pois diversão, vício, pecado e doença eram contíguos. Divertimento e doença, faces de uma mesma moeda, desgastavam os corpos, prejudicavam o trabalho, suscitavam desobediências e castigos, demandavam cuidados, eram combatidos.

\section{REFERÊNCIAS}

ALGRANTI, Leila Mezan. Tabernas e botequins. Cotidiano e sociabilidades no Rio de Janeiro (1808-1821). Acervo, Rio de Janeiro, v. 24, n. 2, p. 25-42, jul./dez. 2011. Disponível em: http://hdl.handle.net/20.500.11959/brapci/43616. Acesso em: 02 out. 2020.

ACSM - Arquivo Casa Setecentista de Mariana, códice 210, auto 5259, $2^{\circ}$ of., 1782.

AEAM - Arquivo Eclesiástico da Arquidiocese de Mariana. Livro de Devassa, fl. 3v, 4, $5 \mathrm{v}$ e $6,1722-1723$.

AEAM - Arquivo Eclesiástico da Arquidiocese de Mariana. Livro de Devassa, fl. 131v, Freguesia de Guarapiranga, 1726.

AEAM - Arquivo Eclesiástico da Arquidiocese de Mariana. Livro de Devassa, Z 02, fl. $115 \mathrm{v}, 1727$.

AHCMM - Arquivo Histórico da Câmara Municipal de Mariana, códice 462, fl. 171v, 1775. AHCMM - Arquivo Histórico da Câmara Municipal de Mariana, códice 462, fl. 228v, 1791. AHCMM - Arquivo Histórico da Câmara Municipal de Mariana, códice 462, fl. 196v, 1780. AHMI - Arquivo Histórico do Museu da Inconfidência, códice 163, auto 2214, $1^{\circ}$ of., 1741. AHMI - Arquivo Histórico do Museu da Inconfidência, códice 445, auto 9336, $1^{\circ}$ of., 1742a. AHMI - Arquivo Histórico do Museu da Inconfidência, códice 449, auto 9476, $1^{\circ}$ of., 1742 b. AHMI - Arquivo Histórico do Museu da Inconfidência, códice 450, auto 9496, 1ºf., 1747. AHMI - Arquivo Histórico do Museu da Inconfidência, códice 177, auto 3180, 2ºf., 1749. AHMI - Arquivo Histórico do Museu da Inconfidência, v. IV, 1771. 
AHMI - Arquivo Histórico do Museu da Inconfidência, códice 445, auto 9347, $1^{\circ}$ of., Vila Rica, 1800.

ANNAES DA BIBLIOTHECA NACIONAL DO RIO DE JANEIRO, 1936.

APM - Arquivo Público Mineiro, CMOP, Câmara Municipal de Ouro Preto, DNE, Documentação Não Encadernada, caixa 05, doc 29, 1733.

APM - Arquivo Público Mineiro, CMOP, Câmara Municipal de Ouro Preto, DNE, Documentação Não Encadernada, caixa 24, doc 38, 1751.

BLUTEAU, Raphael. Vocabulario portuguez \& latino: aulico, anatomico, architectonico... Coimbra: Collegio das Artes da Companhia de Jesus; Lisboa: Officina de Pascoal da Sylva, 1712-1728. v. 3.

DAZILLE, Jean-Barthélem. Observações sobre as enfermidades dos negros, suas causas, seus tratamentos, e os meios de as prevenir. Tradução de Antonio José Vieira de Carvalho. Lisboa: Typographia Chalcographica, Typoplastica, e Litterraria do Arco do Cego, 1801.

DIAS, Maria Odila Leite da Silva. Corpo, natureza e sociedade nas Minas (1680-1730). Projeto História, São Paulo, n. 25, p. 325-359, dez. 2002.

FERREIRA, Luís Gomes. Erário Mineral. FURTADO, Júnia Ferreira (org.). Belo Horizonte: Fundação João Pinheiro, Centro de Estudos Históricos e Culturais; Rio de Janeiro: Fundação Oswaldo Cruz, 2002. v. 1, v. 2.

FIGUEIREDO, Luciano. Pinga, cachaça, jeritiba. Nossa História. Rio de Janeiro: Biblioteca Nacional, ano 2, n. 13, p. 68-72, nov. 2004.

FIGUEIREDO, Luciano Raposo de Almeida. A linguagem da embriaguez: cachaça e álcool no vocabulário político das rebeliões na América Portuguesa. Rev. His., São Paulo, n. 176, 1-25, 2017. Disponível em: https://doi.org/10.11606/issn.2316-9141. rh.2017.114859. Acesso em: 20 set. 2020.

FONSECA, Thais Nívea de Lima e. Educação na América Portuguesa: sujeitos, dinâmicas, sociabilidades. História: Questões \& Debates, Curitiba, n. 60, p. 15-38, jan./jun. 2014. Disponível em: http://dx.doi.org/10.5380/his.v60i1.38277. Acesso em: 02 out. 2020.

GUIMARÃES, Carlos Magno. Os quilombos, a noite e a aguardente nas Minas coloniais. In: VENÂNCIO, Renato Pinto; CARNEIRO, Henrique (org.). Álcool e drogas na história do Brasil. São Paulo: Alameda, 2005. p. 93-122.

LARA, Silvia Hunold. Campos de violência: escravos e senhores na Capitania do Rio de Janeiro, 1750-1808. Rio de Janeiro: Paz e Terra, 1988.

MACHADO, Roberto et al. Danação da norma: medicina social e constituição da psiquiatria no Brasil. Rio de Janeiro: Edições Graal, 1978. 
MELO, Victor Andrade de. Educação, civilização, entretenimento: o Tivoli - um parque de diversão no Rio de Janeiro do século XIX (1846-1848): das iniciativas missionárias à escola indígena específica e diferenciada. Revista Brasileira de História da Educação, Maringá, v. 20, p. 1-25, 2020a. Disponível em: https://doi.org/10.4025/10.4025/rbhe. v20.2020.e114. Acesso em: 03 out. 2020.

MELO, Victor Andrade de. A educação do corpo nas escolas do Rio de Janeiro do século $X I X$. Rio de Janeiro: 7 Letras, 2020 b.

MORENO, Andrea et al. Gesticulação nobre, sympathica e attitude digna: educação do corpo na formação de professoras (Escola Normal Modelo da Capital, Belo Horizonte, 1906-1930). Rev. Bras. Hist. Educ., Campinas, v. 12, n. 1, p. 221-242, jan./abr. 2012.

ROMEIRO, Adriana; BOTELHO, Angela Vianna. Dicionário histórico das Minas Gerais: período colonial. Belo Horizonte: Autêntica, 2003.

ROSA, Maria Cristina; SILVA E SANTOS, Marcone Rodrigues da. Violência, saúde e adoecimento dos corpos na Comarca de Vila Rica, século XVIII. Hist. Cienc. SaudeManguinhos, Rio de Janeiro, v. 27, n. 1, jan./mar. 2020. Disponível em: http://dx.doi. org/10.1590/s0104-59702020000100005. Acesso em: 28 set. 2020.

SILVA, Maria Beatriz Nizza da. A cultura luso-brasileira: da reforma da universidade à independência do Brasil. Lisboa: Editorial Estampa, 1999.

SILVA, Valquiria Ferreira da. De cabeça de porco à bebida de negro: um estudo sobre a produção e o consumo da aguardente nas Minas Gerais no século XVIII. 2015. 247p. Dissertação (Mestrado em História) - Faculdade de Filosofia e Ciências Humanas, Universidade Federal de Minas Gerais, Belo Horizonte, 2015.

SOARES, Carmen Lúcia. Educação do corpo. In. GONZÁLEZ, Fernando Jaime; FENSTERSEIFER, Paulo Evaldo (org.). Dicionário Crítico de Educação Física. Ijuí: Unijuí, 2014. p. 219-225.

SOARES, Carmen Lúcia. Notas sobre a educação no corpo. Educar, Curitiba, n. 16, p. 43-60, 2000.

SOARES, Priscila Gonçalves et al. Linha de pesquisa "História e Memória do Lazer" do Programa de Pós-Graduação Interdisciplinar em Estudos do Lazer da UFMG: produção e análise. Licere, Belo Horizonte, v. 23, n. 3, p. 687-708, set. 2020. Disponível em: https:// doi.org/10.35699/2447-6218.2020.25526. Acesso em: 03 out. 2020.

TABORDA DE OLIVEIRA, Marcus Aurélio (org.). Educação do corpo na escola brasileira. Campinas: Autores Associados, 2006.

VIDE, D. Sebastião Monteiro da. Constituições Primeiras do Arcebispado da Bahia (1707). São Paulo: Typographia 2 de dezembro, 1853. 
VIGARELLO, Georges. O limpo e o sujo: uma história corporal. Tradução de Monica Stahel. São Paulo: Martins Fontes, 1996.

VIGARELLO, Georges. História das práticas de saúde: a saúde e a doença desde a idade média. Tradução de Luís Felipe Sarmento. Lisboa: Editorial Notícias, 2001.

Texto recebido em 04/10/2020.

Texto aprovado em 27/01/2021. 